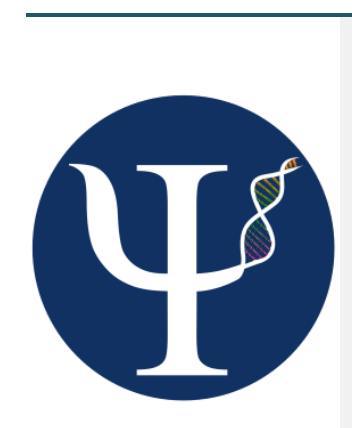

\title{
Validation of the Achievement Goal Questionnaire - Revised in Argentinean university students (A-AGQ-R)
}

Validación del Cuestionario de metas de logrorevisado en estudiantes universitarios argentinos (A-AGQ-R)

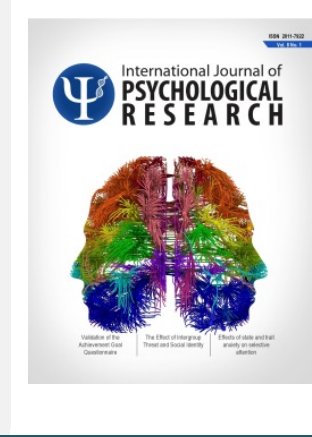

Res e a r ch

Javier Sánchez Rosas ${ }^{\mathrm{a}, *}$

a Laboratory of Psychological and Educational Assessment, Faculty of Psychology, National University of Córdoba, Argentina.

\section{ABSTRACT}

The psychometric properties of a Spanish adaptation of the AGQ-R (Elliot \& Murayama, 2008) were tested in a sample of Argentinean university students (292). The hypothesized factor and dimensional structures of the measure were confirmed and shown to be superior to a host of alternatives. Each of the four achievement goal factors had a high degree of internal consistency. Effects of the four achievement goals scales on task value, social academic self-efficacy, enjoyment, shame, and academic performance, provided support to utility of the scales. The A-AGQ-R provides a measure that attested valid and reliable scores. Finally, these findings provide a validated version of the AGQ-R for its use in Argentinean university students.

\section{RESUMEN}

Se evaluaron las propiedades psicométricas de una adaptación al español del AGQ-R (Elliot \& Murayama, 2008) en una muestra de estudiantes universitarios argentinos (292). Se confirmaron las estructuras factoriales y dimensionales hipotetizadas, las cuales también demostraron ser superiores a otros modelos alternativos. Los valores de consistencia interna para cada escala fue elevada. Se obtuvo evidencias de la utilidad de las escalas al evaluar los efectos de las cuatro metas de logro sobre valor de la tarea, autoeficacia social académica, disfrute, vergüenza y rendimiento académico. De esta manera, el A-AGQ-R sería un instrumento con buenas propiedades de validez y confiabilidad. Finalmente, estos resultados brindan una versión validada del AGQ-R para su uso en estudiantes universitarios argentinos.
Article history:

Received: 28-06-2014

Revised: 14-09-0000

Accepted: 15-12-2014

Key words:

achievement goal, adaptation, validity, achievement emotion, task value, self-

efficacy
Palabras clave: metas de logro, adaptación, validez, emoción de logro, valor de la tarea, autoeficacia

\footnotetext{
* Corresponding author: Javier Sánchez Rosas, Laboratory of Psychological and Educational Assessment, Faculty of Psychology, National University of Córdoba, Argentina.Email address: jsanchezrosas@psyche.unc.edu.ar
} 


\section{INTRODUCTION}

During the last three decades, the achievement goals have been a fundamental construct of the achievement motivation literature. Different conceptual models of achievement goals have been developed in this time: dichotomous, trichotomous, $2 \times 2$ (for a review see Elliot, 2005) and more recently $3 \times 2$ (Elliot, Murayama, \& Pekrun, 2011). Likewise, there is a large variety of selfreported instruments that allow measuring the tendency to adopt achievement goals (Elliot \& Church, 1997; Elliot \& McGregor, 2001; Harackiewicz et al., 2008; Midgley et al., 2000; Nicholls, Patashnick, \& Nolen, 1985; Skaalvik, 1997). According to a recent meta-analysis (Huang, 2011) the most used instruments are the AGQ (Achievement Goals Questionnaire, Elliot \& McGregor, 2001) and its improved version AGQ-R (Achievement Goal Questionnaire-Revised, Elliot \& Murayama, 2008). Additionally, the AGQ is the most used instrument to measure the $2 \times 2$ achievement goals model. This model made a more precise distinction of achievement goals including approach and avoidance components to mastery and performance goals.

Different Spanish adaptations of the AGQ can be mentioned. González, Donolo, Rinaudo and Paoloni (2010) obtained acceptable fit indexes and internal consistency values between .75 and .87 (alpha). These researchers used the Finney, Pieper and Barron (2004) achievement goal questionnaire, which is an adaptation to general academic context of the original questionnaire designed by Elliot and McGregor (2001). Additionally, Moreno, GonzálezCutre and Sicilia (2007) validated the $2 \times 2$ AGPES (Guan, Xiang, McBride, \& Bruene, 2006) in the Spanish context adapted from the AGQ (Elliot \& McGregor, 2001) to evaluate achievement goals in physical education. They obtained marginally acceptable fit values and internal consistency between .67 and .72 (alpha).

Even though both versions adapted to Spanish assess the $2 \times 2$ achievement goals model (Elliot, 1999; Elliot \& McGregor, 2001), they take an initial version (AGQ) about which Elliot and Murayama (2008) formulated a set of observations and elaborated a revised version of the measure (AGQ-R) that allowed to improve limitations on measurement of achievement goals.

In the present study, the psychometric properties of a Spanish version of the AGQ-R (Elliot \& Murayama, 2008) adapted in a sample of Argentinean university students are assessed (namely A-AGQ-R).

\subsection{The $2 \times 2$ achievement goal framework}

In the literature, the distinction between approach motivation and avoidance motivation was incorporated in the first formal model of achievement motivation (Lewin's theory of resultant valence), and has been central in other theories that explain the achievement behavior since then (for a review see Elliot, 2005). Elliot was the first theorist who introduced such a distinction in his trichotomous achievement goal framework (Elliot \& Harackiewicz, 1996). Specifically, he bifurcated to the conventional performance goal into conceptually independent approach and avoidance goals, and posited three separate achievement goals: a mastery goal focused on the development of competence or the attainment of task mastery, a performance-approach goal focused on the attainment of normative competence, and a performance-avoidance goal focused on the avoidance of normative incompetence.

In subsequent work Elliot (1999) proposed a 2 $\times 2$ achievement goal framework which incorporated the approach-avoidance distinction within mastery goals as well as performance goals. Whereas mastery-approach goals entail striving to develop one's skills and abilities, advance one's learning, understand material, or master a task, masteryavoidance goals entail striving to avoid losing one's skills and abilities, forgetting what one has learned, misunderstanding material, or leaving a task incomplete (Elliot \& McGregor, 2001).

\subsection{Achievement goals and related outcomes}

Accumulated evidence has shown that the adoption of these goals is driven by differential antecedents and leads to differential patterns of cognitive, affective, and behavioral consequences (Elliot, 1999; Schunk, Pintrich, \& Meece, 2008). Traditionally, mastery-approach and performanceavoidance goals have demonstrated their positive and negative relations on learning processes, respectively. Nevertheless, the role of mastery-avoidance and performance-approach tend to be more ambiguous because of their focus in negative results and normative components, respectively (Elliot, 1999).

In two studies, the achievement goals (mastery, performance-approach, and performanceavoidance) were shown to predict discrete achievement emotions (Pekrun, Elliot, \& Maier, 2006; Pekrun, Elliot, \& Maier, 2009). Approachmastery was a positive predictor of enjoyment, and a negative predictor of boredom and anger. On the other hand, performance-approach predicted hope and 
pride, whereas performance-avoidance was a positive predictor of hopelessness, anxiety and shame.

Furthermore, Wigfield (1994) suggested that individuals' self-efficacy and task value are posited to have direct influences on their achievement goals. For example, Greene, Miller, Crowson, Duke, and Akey (2004) and Liem, Lau, and Nie (2008) found a positive effect of the task value on the mastery goal. Additionally, self-efficacy was found to have direct effects on the two types of performance goal and mastery goal (mastery-approach). The effect was positive for the mastery-approach and the performance-approach goal but negative for the performance-avoidance goal (Liem et al., 2008).

Finally, relations between achievement goals and performance attainment have been somewhat consistent across studies, and discernable patterns may be ascertained. Performance-approach goals are often positive predictors, performance-avoidance goals are typically negative predictors, and mastery goals are sometimes positive predictors and are sometimes unrelated, perhaps depending on type of task, age of participants, and type of analysis conducted (Pekrun et al., 2009).

\subsection{Achievement Goal Questionnaire-Revised}

Elliot and Murayama (2008) identified several specific problems with the measurement of achievement goals and illustrated these problems, focusing primarily on Elliot and McGregor's (2001) Achievement Goal Questionnaire (AGQ) to attend to these problems. In general, the instruments include measurements of other constructs such as value, concern, preference or a success definition. According to this, Hulleman, Durik, Schweigert and Harackiewicz (2008) identified 243 correlational studies that measured achievement goals using self-report inventories and conducted a meta-analysis to determine the construct validity of achievement goal measures and concluded that achievement goal researchers used similar labels for conceptually different constructs. Elliot and Murayama (2008) corrected these types of problems in the AGQ-R, for example, changing the item "It is important for me to do better than other students" to the item "My goal is to perform better than the other students". Additionally, they stayed that achievement goal measures should keep the goal separated from the reason why the person is pursuing the goal, include normative comparisons in both performance-goals dimensions (approach-avoidance) according to definition of this type of goals, and should not include affective content as part of the items that assess goals. The final AGQ$R$ (Elliot \& Murayama, 2008) version allows to assess the four dimensions of the $2 \times 2$ achievement goal framework.

Elliot and Murayama (2008) examined the factor structure of the AGQ-R and compared the hypothesized model of four related factors (see Figure 1) to a series of alternative three- and two-factor models (Elliot \& McGregor, 2001).

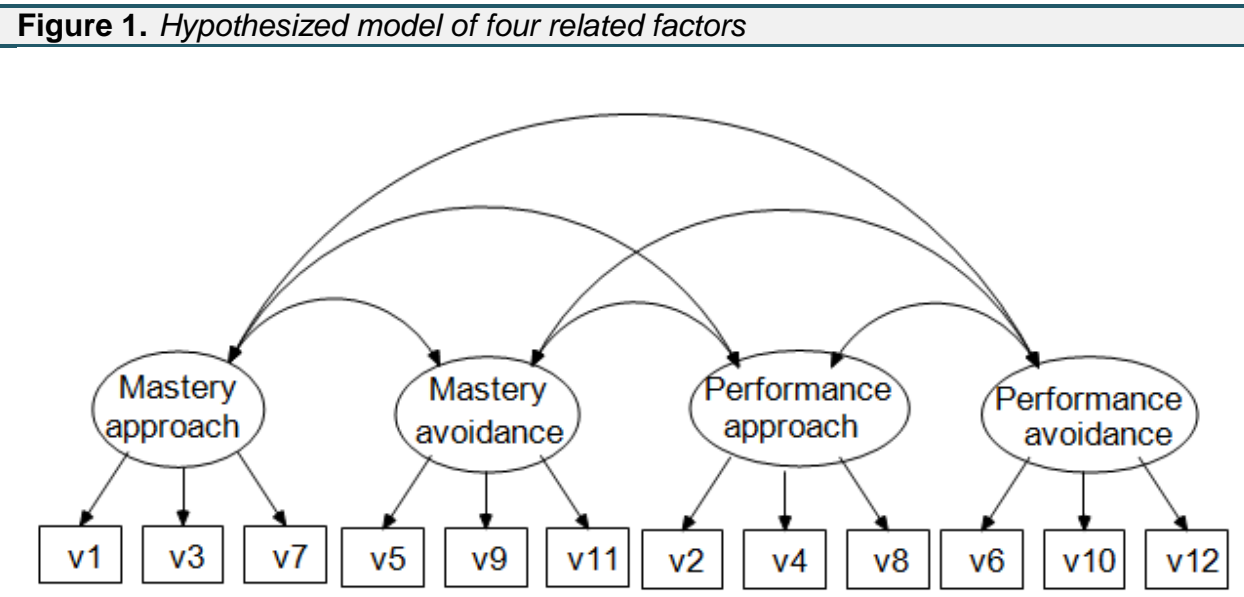

Note: V1-V12 represents the individual items of the scale (numbers indicate the order of items in the questionnaire).

Additionally, they moved beyond the analysis of factor structure to an analysis of dimensional structure, testing the hypothesis that the four goals represent combinations of two underlying dimensions (see Figure 2).
This second, hypothesized dimensional model was also compared to alternative dimensional models. The hypothesized factor and dimensional structures of the measure were confirmed and shown to be superior to a host of alternatives. 
Finally, the predictive utility was supported with regard to both the antecedents (need for achievement and fear of failure) and consequences (intrinsic motivation and exam performance) of the four achievement goals, and optimal values of internal consistency were found for each scale.
In the present research, the purposes are (a) to examine factor and dimensional structure, (b) to obtain data of internal consistency from each scale, and (c) to provide test-criterion evidence of a Spanish version of the AGQ-R (Elliot \& Murayama, 2008) adapted in a sample of Argentinean university students.

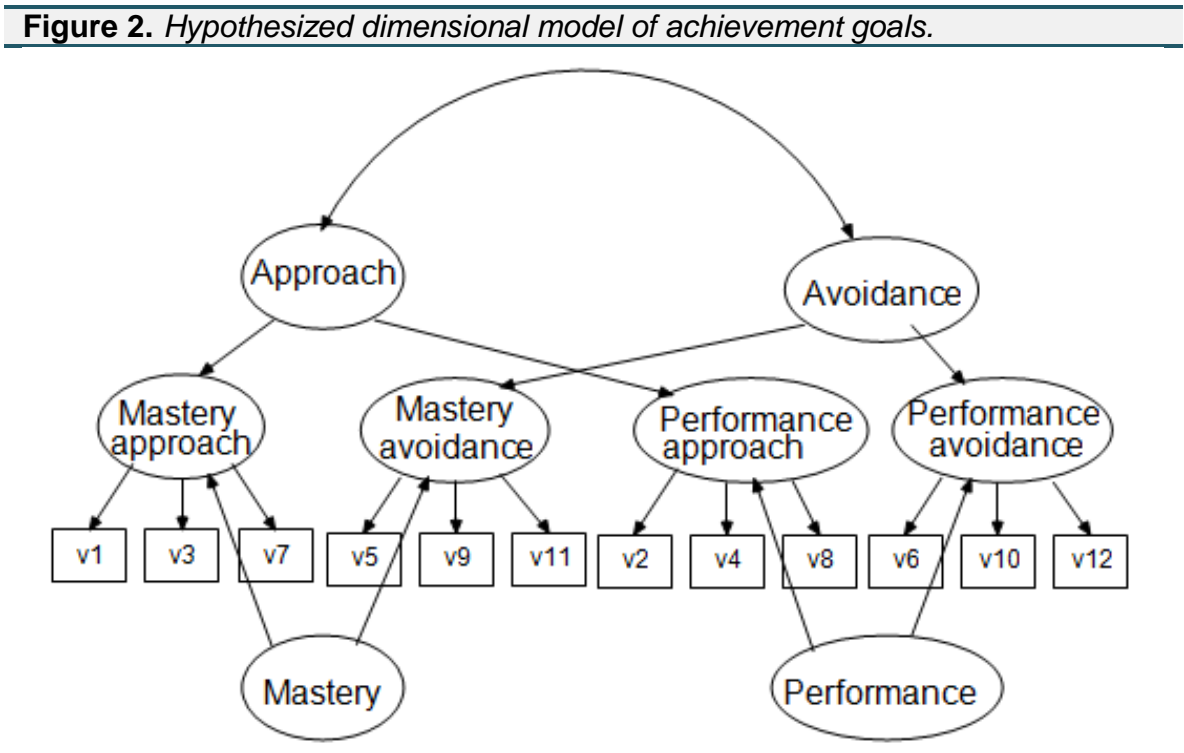

\section{METHOD}

\subsection{Design}

A psychometric, instrumental, correlational-explicative, transversal design was developed (Montero \& León, 2007).

\subsection{Participants}

The sample was self-selected because the guest people decided whether or not to participate in the study (Sterba \& Foster, 2008). A total of 335 (85\% female; $M=25.10$ years, $S D=10.14$ ) Argentinean undergraduates from ten different faculties of the National University of Córdoba participated in the study (58\% Psychology, 22\% Languages, 5\% Law, $3.1 \% \quad$ Chemistry, $2.4 \% \quad$ Architecture, $2.4 \%$ Engineering, $2.1 \%$ Medical Sciences, $2.4 \%$ Philosophy and Arts, 1\% Astronomy, Mathematics and Physics, 1\% Economy).

\subsection{Measures}

Achievement Goal Questionnaire-Revised (Elliot \& Murayama, 2008). Students must answer 12 items expressing the degree of agreement with each item (items from Spanish version are presented in the Appendix) on a scale of 1 (strongly disagree) to 5 (strongly agree). Subscales and internal consistency original values are: mastery-approach, $\alpha=.84$, mastery-avoidance, $\alpha=.88$, performance-approach, $\alpha$ $=.92$ and performance-avoidance, $\alpha=.94$.

Task value (Pintrich, Smith, García, \& McKeachie, 1993). It assesses student's perception of the extent to which the learning materials and contents are interesting, important, and useful. It has 6 items (I think what I learn in this course will be useful in other) and the original scale presents a good internal consistency $(\alpha=.90)$. Participants answer on a 1 (strongly disagree) to 5 (strongly agree) scale. This scale proved predictive utility respect achievement emotions in university students from Córdoba, Argentina (Sánchez Rosas, Piotti, Sánchez, Pereira, \& Debat, 2011). In the present study, unidimensionality and internal consistency were tested. Acceptable results were obtained $(\mathrm{KMO}=.86,58 \%$ variance accounted and factor loadings $>.70, \alpha=.85$ ).

Social academic self-efficacy (EAS-U, Olaz, 2006). It is a scale developed and validated for university population of Córdoba, Argentina. It assesses student's beliefs about their interpersonal abilities in academic context. It has 7 items (Ask questions to the teacher loudly and in front of your classmates) and the original internal consistency is good ( $\alpha=.84)$. Participants respond on a 1 (I can't do it) to 10 (totally sure I can do it) scale, expressing confidence for do each behavior. Unidimensionality and internal consistency were tested. Good results 
were obtained $(\mathrm{KMO}=.89,66 \%$ variance accounted and factor loadings $>.52, \alpha=.91$ ).

Class emotions. This study employed two adapted scales of the Achievement Emotions Questionnaire (Pekrun, Goetz, Frenzel, Barchfeld, \& Perry 2011) for university population of Córdoba (Sánchez Rosas, 2011). On one hand, class-related enjoyment was tested through a 9 items scale (My enjoyment of this class makes me want to participate). Unidimensionality and internal consistency were tested. Acceptable results were obtained $\left[X^{2}(27, N=\right.$ 232) $=50.79, \mathrm{p}=.01, \mathrm{X}^{2} / \mathrm{df}=1.88, \mathrm{CFI}=.94, \mathrm{GFI}=$ .95 , RMSEA $=.06$; $\alpha=.77]$. On the other hand, classrelated shame was tested through a 7 items scale (When I say anything in class I feel like I am making a fool of myself). Unidimensionality and internal consistency were tested. Optimal results were obtained $\left[X^{2}(14, N=232)=20.44, p=.11, X^{2} / d f=\right.$ $1.46, \mathrm{CFI}=.98, \mathrm{GFI}=.98, \mathrm{RMSEA}=.04 ; \alpha=.88]$. Students rate their emotional experiences of enjoyment and shame of classroom learning on a five point Likert scale from 1 (never) to 5 (always).

Academic performance. Grade Point Average in career was obtained. All the scales ask for students about their global experiences respect their subjects.

\subsection{Procedure}

Initially, an official translator accomplished a direct translation from English to the Spanish spoken by the participants of the objective population of the AGQ-R (Elliot \& Murayama, 2008). The response format was adapted to evaluate the agreement degree with each item ranging from 1 (strongly disagree) to 5 (strongly agree). Protocols were elaborated with consent added to the set of selected scales for this study. Participants were contacted via e-mails and social networks, and all they agreed voluntarily to complete the protocols administered to the sample through the online survey system Lime Survey (Perez, 2007).

\subsection{Data analysis}

Confirmatory factor analyses (CFAs) were conducted on the achievement goal items. Following the strategy of Elliot and Murayama (2008), the analyses were conducted on covariance matrices, and the solutions were generated on the basis of maximum-likelihood estimation. Several different indexes to evaluate the fit of the models to the data were used: chi-square degree of freedom ratio ( $x 2 / \mathrm{df})$, comparative fit index (CFI), goodness fit index (GFI), incremental fit index (IFI), and root-mean square error of approximation (RMSEA). The following criteria were used to evaluate the adequacy of model fit: $\mathrm{x} 2 / \mathrm{df} \leq 2.0$ (Hair, Anderson, Tatham, \& Black, 1995), CFI $\geq .90$, $\mathrm{GFI} \geq .90, \mathrm{IFI} \geq .90$, and RMSEA $\leq .08$ (Browne \&
Cudeck, 1993). When multiple models were compared, the Akaike information criterion (AIC) and Bayesian information criterion (BIC) were used as well (the lower those values are, the better the fit is). Also, standardized regression coefficients were interpreted.

In order to provide test-criterion evidence a path model was carried out where achievement goals predict motivation, emotion and performance. The following criteria were used to evaluate the adequacy of model fit: X2/df, CFI, GFI, IFI, RMSEA, and significant path coefficients.

Finally, the internal consistency was estimated using Cronbach's alpha coefficient.

The IBM SPSS Amos 19 (Arbuckle, 2010) program was used to conduct the statistical analysis according to proposed objectives.

\section{RESULTS}

Previously to the central analysis, an initial exploration of all items was conducted to evaluate missing values, univariate and multivariate atypical cases, and normal univariate distributions. Any missing values were found. Then, univariate and multivariate atypical cases by calculating the standard z score for each variable (z scores > 3.29 were considered atypical) and the Mahalanobis distance measure $(p<.001)$, were identified. Forty-three cases were discarded based on these analyses, and final sample was $N=292$. Across variables, the values for asymmetry and kurtosis were between -2 and +2 , which are considered acceptable in order to prove normal univariate distribution (George \& Mallery, 2010).

\subsection{Factorial structure of achievement goals}

\subsubsection{Basic CFAs and internal consistencies.}

The first CFA examined the hypothesized model, which designated that the items for each goal load on their respective latent factors, and all the residuals were uncorrelated. The results from this analysis strongly supported the hypothesized model: all factor loadings were high, and each fit statistic met the criteria for a good fitting model: $[X 2(48, N=292)=$ 58.23, $\mathrm{p}=.148, \mathrm{X} 2 / \mathrm{df}=1.21, \mathrm{CFI}=.99, \mathrm{GFI}=.96, \mathrm{IFI}$ $=.99$, RMSEA $=.027, \mathrm{AIC}=118.2, \mathrm{BIC}=228.5]$ (Figure 3). In this sample all of the subscales demonstrated high levels of internal consistency: for mastery-approach goals, mastery-avoidance goals, performance-approach goals, and performanceavoidance goals, Cronbach's $\alpha=.81, .91, .92$, and .98 , respectively.

\subsubsection{Comparison with alternative models}

Additional CFAs were made in order to examine the fit of alternative models and compare the fit of the hypothesized and alternative models. Six 
alternative models were tested: (a) trichotomous model $A$, in which the performance-approach and performance-avoidance items load on their respective latent factors, and the mastery-approach and masteryavoidance items load together on a third latent factor; (b) trichotomous model $B$, in which the masteryapproach and mastery-avoidance items load on their respective latent factors, and the performanceapproach and performance-avoidance items load together on a third latent factor; (c) trichotomous model C, in which the mastery-approach and performance-approach items load on their respective latent factors, and the mastery-avoidance and performance-avoidance items load together on a third latent factor; (d) trichotomous model D, in which the mastery-avoidance and performance-avoidance items load on their respective latent factors and the masteryapproach and performance-approach items load together on a third factor; (e) a mastery-performance

Figure 3. Hypothesized model of four related factors.

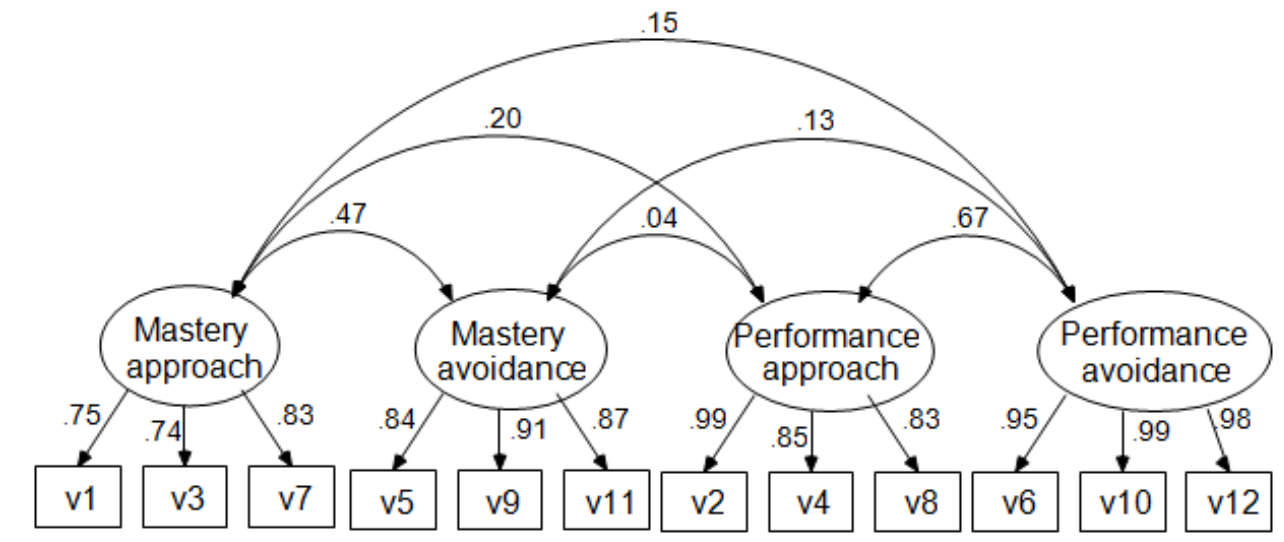

Note: Estimates are standardized. All coefficients are significant $(p<.01)$. Error variables are not represented in order to simplify the presentation.

model in which the mastery-approach and masteryavoidance items load together on one latent variable, and the performance-approach and performanceavoidance items load together on another; and $(f)$ an approach-avoidance model in which the masteryapproach and performance-approach items load together on one latent variable, and the masteryavoidance and performance-avoidance items load together on another.
As may be seen in Table 1, the fit indexes indicate that none of the alternative models provided a good fit to the data, and the hypothesized model provided a far better fit than any of the alternative models. For other hand, although correlations between some latent variables were high (i.e., mastery-approach and mastery-avoidance, $r=.47$; performance-approach and performance-avoidance, $r$ $=.67$ ), data clearly show that the goals within these pairings are not equivalent.

\begin{tabular}{|c|c|c|c|c|c|c|c|c|c|}
\hline Models & $X^{2}$ & $D f$ & CMIN/df & CFI & GFI & IFI & RMSEA & AIC & $B I C$ \\
\hline Hypothesized Model & 58.2 & 48 & 1.21 & .997 & .969 & .997 & .027 & 118.2 & 228.5 \\
\hline Trichotomous Model A & $291.5^{\star \star \star}$ & 51 & 5.71 & .928 & .844 & .928 & .127 & 345.5 & 448.8 \\
\hline Trichotomous Model B & $510.4^{\star \star \star}$ & 51 & 10.01 & .863 & .790 & .863 & .176 & 564.4 & 663.7 \\
\hline Trichotomous Model C & $689.2^{\star \star \star}$ & 51 & 13.51 & .809 & .717 & .810 & .207 & 743.2 & 842.4 \\
\hline Trichotomous Model D & $403.5^{\star \star \star}$ & 51 & 7.91 & .895 & .788 & .895 & .154 & 457.5 & 556.7 \\
\hline $\begin{array}{l}\text { Mastery-performance } \\
\text { model }\end{array}$ & $736.5^{\star \star *}$ & 53 & 13.89 & .796 & .702 & .797 & .211 & 786.4 & 878.3 \\
\hline $\begin{array}{l}\text { Approach-avoidance } \\
\text { model }\end{array}$ & $980.6^{\star \star *}$ & 53 & 18.50 & .723 & .605 & .724 & .245 & 1030.6 & 1122.5 \\
\hline Vote: $N=292, \star \star \star * x<.0$ & & & & & & & & & \\
\hline
\end{tabular}




\subsection{The dimensional structure of achievement goals}

The multiple-indicator correlated traitcorrelated method (MI CT-CM) model. Although the preceding analyses showed that the four-factor model is highly robust, they do not address the $2 \times 2$ structure of achievement goals per se. That is, from a theoretical perspective, the valence of competence (positive for approach or negative for avoidance) should be crossed with the definition of competence (mastery or performance), resulting in four separate factors. CFA alone is silent with regard to this dimensional structure. To test the two-dimensional nature of achievement goals, Elliot and Murayama (2008) applied an MI CT-CM model (Eid, Lischetzke, Nussbeck, \& Trierweiler, 2003) to the data.

In this model (Figure 2), both the valence and definition dimensions of competence are expected to have additive effects on an achievement goal factor. The valence dimension consists of an approach factor and an avoidance factor, only one of which is applicable to any given goal factor; likewise, the definition dimension consists of a mastery factor and a performance factor, only one of which is applicable to any given goal factor. For example, the masteryapproach factor is posited to be explained by both, the mastery factor and the approach factor. Although factors within each dimension can correlate with each other, it is assumed that factors across dimensions (e.g., the approach factor and the performance factor) are uncorrelated. Thus, the valence and definition dimensions each contribute independently to the achievement goal factors. This type of model is sometimes called an additive model, because each component additively contributes to the construct.

To identify the model and following Elliot and Murayama's (2008) specifications, paths from the same second factors were constrained to be equal and fixed the covariance between the mastery and performance factors to 0 . The model provided a good fit to the data: $X^{2}(48, N=292)=58.23, p=.15, x 2 / d f$ $=1.21, \mathrm{CFI}=.99, \mathrm{GFI}=.97, \mathrm{IFI}=.99, \mathrm{RMSEA}=.027$, $\mathrm{AIC}=132.2, \mathrm{BIC}=268.2$, and all path coefficients were significant. These results nicely support the $2 \times 2$ dimensionality of the four achievement goals (Figure 4).

Figure 4. MI CT-CM model of achievement goals.

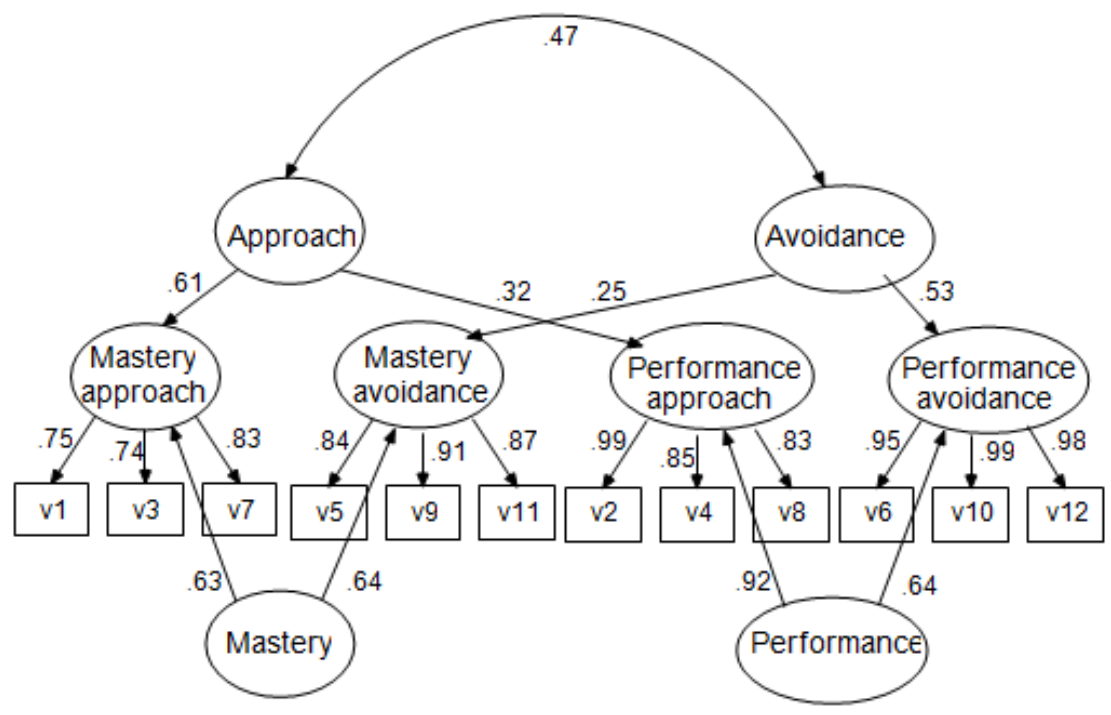

Note: MI CT-CM model of achievement goals." and must to insert in the correct position below the Figure 4 the note "Estimates are standardized. All coefficients are significant $(p<.01)$. Error variables are not represented in order to simplify the presentation.

Figure 4. MI CT-CM model of achievement goals. Estimates are standardized. All coefficients are significant $(p<.01)$. Error variables are not represented in order to simplify the presentation.

\subsubsection{Comparison with alternative models}

The two alternative models are a form of twolevel model, an example of which is depicted in Figure 5. In this model, the four achievement goal factors themselves make up a two-factor structure. There are 
two possible types of two-level structures: (a) a mastery-performance two-level model, in which a mastery factor (consisting of mastery-approach and mastery-avoidance factors) and a performance factor (consisting of performance-approach and performance-avoidance factors) are formed as second-order factors; and (b) an approach-avoidance two-level model, in which an approach factor (consisting of mastery-approach and performanceapproach factors) and an avoidance factor (consisting of mastery-avoidance and performance-avoidance factors) are formed as second-order factors. The critical difference between the MI CT-CM model and these two-level models is that the two-level models derive factors out of only one dimension of the $2 \times 2$ model.

Fitting these models to the data, a worse fit than the MI CT-CM model was obtained (Table 2). Furthermore, the mastery-performance model showed that two residual variances were negative, and two factor loadings were improper $(>1)$. In the approachavoidance model residual variances of performanceapproach and performance-avoidance factors were negative and two standardized factor loadings exceeded the value of one.

\subsection{Test-criterion evidence}

Traditionally, mastery-approach and performance-avoidance goals have demonstrated their positive and negative relations on learning processes, respectively. Nevertheless, the role of mastery-avoidance and performance-approach tend to be more ambiguous because of their focus in negative results and normative components, respectively (Elliot, 1999).

Next, achievement goals effects on motivation, emotion and performance, were considered in order to provide test-criterion evidence.

Figure 5. An example of a two-level model of achievement goals. Mastery-Performance Model.

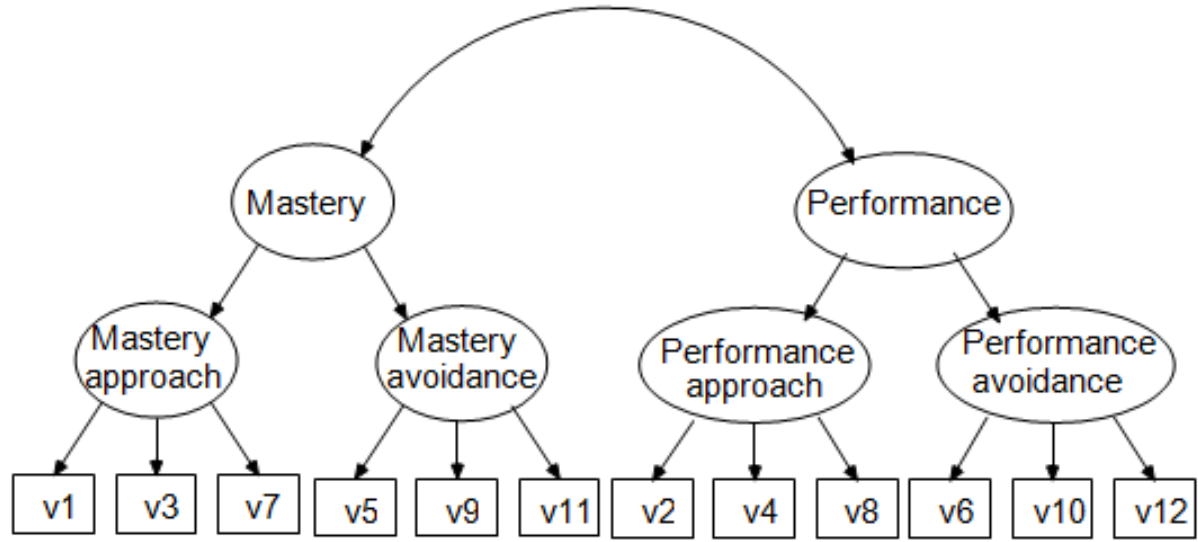

\begin{tabular}{|c|c|c|c|c|c|c|c|c|c|}
\hline Model & $X^{2}$ & $D f$ & $C M I N / d f$ & CFI & GFI & IFI & RMSEA & $A / C$ & $B I C$ \\
\hline MI CT-CM model & 58.23 & 48 & 1.21 & .997 & .969 & .997 & .027 & 132.2 & 268.2 \\
\hline $\begin{array}{l}\text { Mastery-performance } \\
\text { two-level model }\end{array}$ & 63.82 & 49 & 1.30 & .996 & .967 & .996 & .032 & 121.8 & 228.4 \\
\hline $\begin{array}{l}\text { Approach-avoidance } \\
\text { two-level model }\end{array}$ & $112.07^{\star \star \star}$ & 49 & 2.29 & .98 & .94 & .981 & .067 & 170.1 & 276.6 \\
\hline
\end{tabular}

Following to Pekrun et al. (2006, 2009), achievement goals would be considered predictors of social academic self-efficacy, task value, enjoyment, shame, and academic performance. Additionally, selfefficacy and task value would be mediators between achievement goals and emotions and other outcomes, such as performance. A path model hypothesized that (a) mastery-approach is hypothesized to positively predict task value, social academic self-efficacy, and enjoyment; (b) mastery-avoidance may positively predict, tentatively, task value, social academic selfefficacy and enjoyment, whereas mastery-avoidance 
may negatively predict shame; (c) performanceapproach would positively predict social academic self-efficacy, enjoyment, academic performance, and negatively shame; (d) performance-avoidance is hypothesized to negatively predict social academic self-efficacy, academic performance, and positively predict shame; (e) task value and social academic self-efficacy would be positive predictors of enjoyment and negative predictors of shame.

Table 3 shows the correlations between four achievement goals scales and task value, social academic self-efficacy, enjoyment, shame, academic performance.

\begin{tabular}{|c|c|c|c|c|c|c|c|c|c|}
\hline & $\begin{array}{l}\text { ma- } \\
\text { ap }\end{array}$ & ma-av & pe-ap & pe-av & sas & task & cjo & csh & ap \\
\hline ma-ap & - & & & & .09 & $.51^{\star \star}$ & $.22^{\star \star}$ & -.10 & -.02 \\
\hline ma-av & $.41^{* *}$ & - & & & -.04 & $.27^{\star \star}$ & .10 & -.08 & -.05 \\
\hline pe-ap & $.20^{* *}$ & .04 & - & & $-.13^{\star}$ & $.15^{\star}$ & $.12^{*}$ & $.23^{\star \star}$ & .01 \\
\hline pe-av & $.13^{*}$ & $.12^{*}$ & $.67^{* *}$ & - & $-.18^{\star \star}$ & .06 & .05 & $.25^{\star \star}$ & $-.16^{\star \star}$ \\
\hline$M$ & 13.62 & 11.31 & 6.67 & 8.16 & 37.68 & 23.68 & 30.34 & 16.60 & 6.13 \\
\hline SD & 1.63 & 3.54 & 3.64 & 4.22 & 15.77 & 3.34 & 5.10 & 7.13 & 1.48 \\
\hline
\end{tabular}

Note: $N=292$. ma-ap = mastery-approach; ma-av = mastery-avoidance; pe-ap = performanceapproach; pe-av = performance-avoidance; sas = social academic self-efficacy; task = task value; cjo = class enjoyment $;$ csh = class shame $;$ ap = academic performance $.{ }^{*} p<.05,{ }^{* *} p<.01$.

Figure 6. Achievement goals model predicting motivation, emotions and performance.

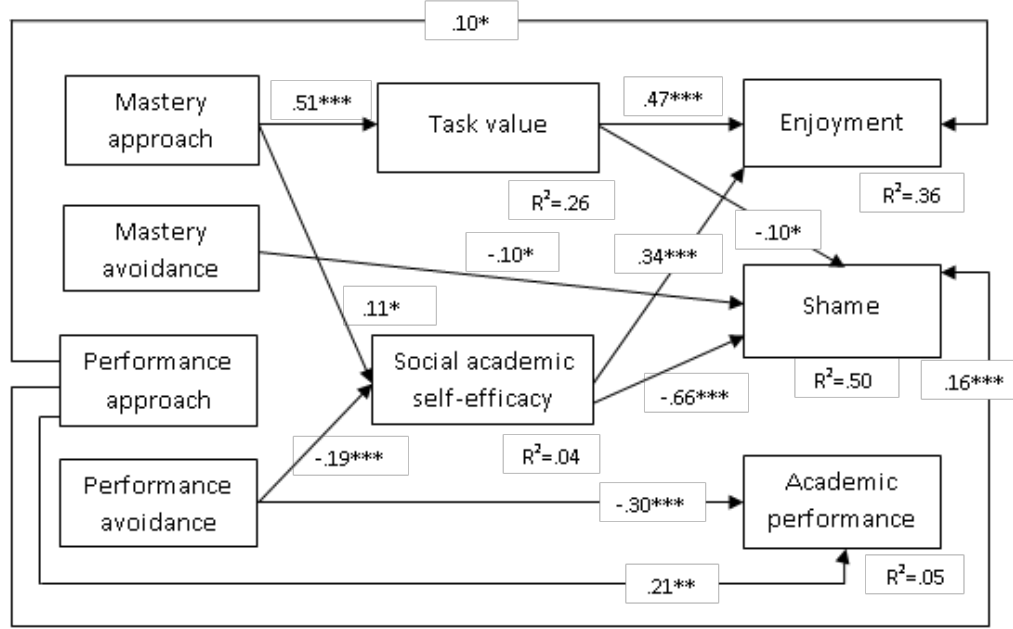

Note: Estimates are standardized. Indicator variables, error variables, and correlations between error variables are not represented in order to simplify the presentation. ${ }^{\star} p<.05,{ }^{\star \star} p<.01$, ${ }^{\star \star \star} p<$ .001 .

In an initial test of the path model, all hypothesized paths were significant with the exceptions of that between mastery-approach and enjoyment, mastery-avoidance and task value, social academic self-efficacy and enjoyment, performanceapproach and social academic self-efficacy, performance-avoidance and shame. The model was thus tested in the final analysis with this path removed. Suggestions of Pérez, Medrano and Sánchez-Rosas (2014) in order to interpret the fit indexes, direct and indirect effects were followed. The model provided a good fit to the data: $X 2(18, N=292)=23.56, p=.17$, $\mathrm{X} 2 / \mathrm{df}=1.30, \mathrm{CFI}=.99, \mathrm{GFI}=.98, \mathrm{IFI}=.99, \mathrm{RMSEA}=$ .033 , and all path coefficients were significant. Mastery-approach was a positive predictor of task value $(\beta=.51)$ and social academic self-efficacy $(\beta=$ .11), whereas mastery-avoidance was a negative predictor of shame $(\beta=-.10)$. For other hand, performance-approach goals were a positive predictors of enjoyment $(\beta=.10)$, shame $(\beta=.16)$, and academic performance $(\beta=.21)$. Lastly, performance-avoidance was a negative predictor of 
both social academic self-efficacy $(\beta=-.19)$ and academic performance $(\beta=-.30)$. These results nicely support the predictive utility of the four achievement goals. See Figure 6 for a pictorial summary of these findings.

\section{DISCUSSION}

In this research, reported results provide evidence of the structural validity of the A-AGQ-R. Specifically, the hypothesized four-factor structure and the hypothesized two-dimensional model of the achievement goal items were confirmed. In effect, the hypothesized four-factor model provided a good fit to data and was found to be better than a series of alternative models with three and two-factor structures. The additive model, in which competence and valence dimensions contribute to explain each factor, also fits the data better than two types of alternative models that resulted inadmissible. Correlations between mastery-approach and masteryavoidance, and performance-approach and performance-avoidance goals tend to be moderate and high correlated, whereas other possible combinations (for example, mastery-approach and performance-approach goals) tend to be low or null correlated. On the one hand, this correlation is to be expected, because these constructs not only share a competence-based component (i.e., an interpersonal standard of evaluation) but are also commonly (and increasingly) measured with items containing substantial semantic overlap (e.g., "My goal is to perform better than the other students" and "My goal is to avoid performing poorly compared to others"; Elliot \& Murayama, 2008). Nonetheless, recent research (Murayama, Elliot, \& Yamagata, 2011) provided evidence supporting the separation of performanceapproach and performance-avoidance goals across different age groups and countries and documented factorial invariance among them. These findings fit nicely with theoretical models emphasizing the independence of approach and avoidance motivation at the level of biological structure and function (Elliot \& Thrash, 2002).

Additionally, scales reliability proved the homogeneity of the measures made by the combination of items integrating each factor. Each of the four achievement goal factors had a high degree of internal consistency.

Most of the hypotheses of a model where achievement goals predict the motivation, emotion and performance, were supported. Mastery-approach had a positive, direct effect on task value and social academic self-efficacy, whereas mastery-approach had an indirect effect through task value on enjoyment $(\beta=.28)$. The effect size for mastery-approach on task value was large. In consequence, this type of goal is a motivational force that importantly affects the importance and utility perceptions, which in turn affect the enjoyment. Performance-avoidance had a negative, direct effect on social academic self-efficacy and academic performance. Additionally, performance-avoidance had an indirect effect through social academic self-efficacy on shame $(\beta=.13)$. Consequently, performance-avoidance goals would contribute to the increase of worries related to a poor achievement (shame), via the decrease of the confidence in the performance of needed social behaviors to obtain an adequate academic achievement (social academic self-efficacy). These results are consistent with other reported in the literature (Greene et al., 2004; Liem et al., 2008; Pekrun et al., 2006, 2009) and highlight the positive and negative of mastery-approach and performance-avoidance on motivation, emotion and achievement.

On the other hand, although masteryavoidance correlated with task value, it did not emerge as a predictor in the path model. Moreover, masteryavoidance was not a predictor of social academic selfefficacy and enjoyment, but had a negative, weak effect on shame. This type of goal entails striving to avoid a potential negative outcome (Elliot \& McGregor, 2001), for example, making a mistake, misunderstanding material, forgetting what one has learned. When a negative outcome is achieved shame is aroused. Therefore, students could experience shame as consequence of being focused on avoiding an incomplete mastery. As mentioned above, the positive and negative components of the goal may cancel each other out, leading to neither positive nor negative consequences (Elliot \& Murayama, 2008). This could be the reason for the absence of significant paths on task value, social academic self-efficacy and enjoyment.

As well as mastery-avoidance, the role of performance-approach tends to be ambiguous because of their discordant components (Elliot, 1999; Elliot \& Murayama, 2008). Focus on the possibility of a positive outcome could have negative effects assigned to the normative comparison. A negative weak correlation between performanceapproach and social academic self-efficacy was found, but this goal did not predict social academic selfefficacy. Nevertheless, performance-approach was a positive predictor of enjoyment, academic performance, and shame. On one hand, this may be due to the effect of approach component on enjoyment and achievement. On the other hand, the positive effect on shame could be due to the normative component of performance goals. 
R E S E A R C H

Finally, it is worth mentioning both the positive and negative effects of task value and social academic self-efficacy on enjoyment and shame respectively, and the role of mastery-approach and performanceavoidance as antecedents of those two motivational constructs. Again, as mentioned in the literature, mastery-approach and performance-avoidance demonstrate their power to encourage and diminish achievement motivation and emotion.

In interpreting the study's findings, it is important to note to its limitations. The findings might not be generalizable to all Spanish-speaking population of other countries different from Argentina. Also, psychometric analyses of the A-AGQ-R were carried out on a sample of Argentinean university students. Although this study has laid a foundation for studies in Argentinean university students, further studies could validate this A-AGQ-R across different age groups, Spanish-speaking population or address gender differences.

Another important limitation is related to the treatment of the ordinal variables of the measures used here. In the future, CFA should calculate a polichoric matrix instead a Pearson covariance matrix. Even, internal consistencies of each factor should be estimated through ordinal alpha, and not by Cronbach alpha coefficients based in Pearson correlations. However, ordinal variables with many categories, such as 5-point Likert-type scales of agreement used here, are usually safely treated as continuous. In practice, most researches treat ordinal variables with 5 or more categories as continuous, and there is some evidence to suggest this is not likely to result in much practical impact on results (e.g., Babakus, Ferguson, \& Joreskog, 1987; Dolan, 1994; Hutchinson \& Olmos, 1998; Johnson \& Creech, 1983).

In conclusion, the A-AGQ-R provided evidence of factor and dimensional structure, internal consistency from each scale, and provided predictive utility evidence. Moreover, psychometric properties of this adapted version of the AGQ-R (Elliot \& Murayama, 2008) for undergraduates tested in a sample of Argentinean university students are promising. The A-AGQ-R contributes to the research on achievement motivation and will be useful in studies that include achievement emotions, motivational constructs and achievement outcomes in university students.

\section{ACKNOWLEDEGEMENTS}

I would like to thank Andrew Elliot for his comments of earlier versions of this manuscript and Kou Murayama for his assistance with the statistical analyses.

Sánchez Rosas (2015)

int.j.psychol.res. 7 (2)

\section{REFERENCES}

Arbuckle, J.L. (2010). IBM SPSS Amos 19 User's Guide. Chicago, IL: IBM.

Babakus, E., Ferguson, C. E. \& Joreskog, K G, (1987). The sensitivity of confirmatory maximum likelihood factor analysis to violations of measurement scale and distributional assumptions. Journal of Marketing Research, 24, 2228.

Dolan, C. V. (1994), Factor analysis of variables with $2,3,5$, and 7 response categories: A comparison of categorical variable estimators using simulated data. British journal of Mathematical and Statistical Psychology, 47, 309-326.

Eid, M., Lischetzke, T., Nussbeck, F. W., \& Trierweiler, L. I. (2003). Separating trait effects from traitspecific method effects in multitraitmultimethod models: A multiple-indicator CT-C (M-1) model. Psychological Methods, 8, 3860.

Elliot, A. J. (1999). Approach and avoidance motivation and achievement goals. Educational Psychologist, 34, 149-169.

Elliot, A. J. (2005). A conceptual history of the achievement goal construct. En Andrew J. Elliot \& Carol Dweck (eds.). Handbook of competence and motivation, 52-72. New York, London: The Guilford Press.

Elliot, A. J., \& Church, M. A. (1997). A hierarchical model of approach and avoidance achievement motivation. Journal of Personality and Social Psychology, 72, 218232.

Elliot, A. J., \& Fryer, J. W. (2008). The goal construct in psychology. In J. Shah \& W. Gardner (Eds.), Handbook of motivational science (pp. 235-250). New York: Guilford Press.

Elliot, A. J., \& Harackiewicz, J. M. (1996). Approach and avoidance achievement goals and intrinsic motivation: A mediational analysis. Journal of Personality and Social Psychology, 70, 461- 475.

Elliot, A. J., \& McGregor, H. A. (2001). A $2 \times 2$ achievement goal framework. Journal of Personality and Social Psychology, 80, 501519.

Elliot, A. J., \& Murayama, K. (2008). On the measurement of achievement goals: Critique, illustration, and application. Journal of Educational Psychology, 100, 613-628.

Elliot, A. J., \& Thrash, T. M. (2002). Approachavoidance motivation in personality: Approach and avoidance temperaments and goals.

PP. $10-23$ 
Journal of Personality and Social Psychology, 82, 804-818.

George, D., \& Mallery, M. (2010). SPSS for Windows Step by Step: A Simple Guide and Reference, 17.0 update (10a ed.) Boston: Pearson.

González, A. J., Donolo, D. S., Rinaudo, M. C., \& Paoloni, P. V. (2010). Metas de logro y autodeterminación en universitarios: diferencias individuales y perfiles motivacionales. REME, 13, 34, 4.

Greene, B. A., Miller, R.B., Crowson, M., Duke, B. L. \& A key, K. L. (2004). Predicting high school student's cognitive engagement and achievement: Contributions of classroom perception and motivation. Contemporary educational psychology, 29(4), 462-482.

Guan, J., Xiang, P., McBride, R., \& Bruene, A. (2006). Achievement goals, social goals and students' reported persistence and effort in high school physical education. Journal of Teaching in Physical Education, 25, 58-74.

Harackiewicz, J. M., Durik, A. M., Barron, K. E., Linnenbrink-Garcia, L., \& Tauer, J. M. (2008). The role of achievement goals in the development of interest: Reciprocal relations between achievement goals, interest, and performance. Journal of Educational Psychology, 100, 105-122.

Huang, C. (2011). Achievement Goals and Achievement Emotions: A Meta-analysis. Educational Psychology Review, 23, 1-30.

Hulleman, C. S., Durik, A. M., Schweigert, S. B., \& Harackiewicz, J. M. (2008). Task values, achievement goals, and interest: An integrative analysis. Journal of Educational Psychology, 100, 398-416.

Hutchinson, S, R., \& Olmos, A (1998). Behavior of descriptive fit indexes in confirmatory factor analysis using ordered categorical data. Structural Equation Modeling: A Multidisciplinary Journal, 5, 344-364.

Johnson, D. R., \& Creech, J.C. (1983) Ordinal measures in multiple indicator models: A simulation study of categorization error. American Sociological Review, 48, 398-407.

Liem, A. D., Lau, S. \& Nie, Y. (2008). The role of selfefficacy, task value, and achievement goals in predicting learning strategies, task disengagement, peer relationship, and achievement outcome. Contemporary Educational Psychology, 33, 486-512.

Midgley, C., Maehr, M. L., Hruda, L. Z., Anderman, E., Anderman, L., Freeman, K. E., et al. (2000). Manual for the Patterns of Adaptive Learning Scales. Ann Arbor: University of Michigan.
Available

at http://www.umich.edu/\%7Epals/manuals.html.

Montero, I., \& León, O. (2007). A Guide for Naming Research Studies in Psychology. International Journal of Clinical and Health Psychology, 7, 847-862.

Moreno, J. A., González-Cutre, D., \& Sicilia, A. (2007). Metas de logro $2 \times 2$ en estudiantes españoles de EF. Revista de Educación, 347, 299-317.

Murayama, K., Elliot, A., \& Yamagata, S. (2011). Separation of performance-approach and performance-avoidance achievement goals: A broader analysis. Journal of Educational Psychology, 103(1), 238-256.

Nicholls, J. G., Patashnick, M., \& Nolen, S. B. (1985). Adolescents' theories of education. Journal of Educational Psychology, 77, 683-692.

Olaz, F. (2006). Construcción de una escala de autoeficacia para estudiantes universitarios. Comunicación presentada en el primer encuentro nacional de Evaluación Psicológica y Educativa. Córdoba: Universidad Nacional de Córdoba.

Pekrun, R., Elliot, A. J., \& Maier, M. A. (2006). Achievement goals and discrete achievement emotions: A theoretical model and prospective test. Journal of Educational Psychology, 98, 583-597.

Pekrun, R., Elliot, A. J., \& Maier, M. A. (2009). Achievement Goals and Achievement Emotions: Testing a Model of Their Joint Relations With Academic Performance. Journal of Educational Psychology, 101, 115135.

Pekrun, R., Goetz, T., Frenzel, A., Barchfeld, P., \& Perry, P. (2011). Measuring emotions in students' learning and performance: The Achievement Emotions Questionnaire (AEQ). Contemporary Educational Psychology, 36, 36-48.

Pérez, C. J. M. (2007). Manual de Usuario de la plataforma de encuestas en línea: Lime Survey, Versión 1.0, Licencia de Documentación Libre GNU.

Pérez, E., Medrano, L., \& Sánchez Rosas, J. (2014). Path Analysis: conceptos básicos y ejemplos de aplicación. Revista de la Asociación Argentina de Ciencias del Comportamiento, 5, 52-66.

Pintrich, P., Smith, D., García, T., \& McKeachie, W. (1993). Reliability and predictive validity of the Motivated Strategies for Learning Questionnaire (MSLQ). Educational and Psychological Measurement, 53, 801-813. 
Sánchez Rosas, J. (2011). Cómo evaluar las emociones académicas. Adaptación del Cuestionario de Emociones de Logro. III Congreso de Psicología de la Facultad de Psicología de la Universidad Nacional de Córdoba.

Sánchez Rosas, J., Piotti, A., Sánchez, V., Pereira, A., \& Debat, E. (2011). Implicancias del interés, la importancia y la utilidad de los materiales y contenidos de aprendizaje para las emociones académicas. III Congreso de Psicología de la Facultad de Psicología de la Universidad Nacional de Córdoba.

Schunk, D. H., Pintrich, P. R., \& Meece, J. L. (2008). Motivation in education: Theory, research, and applications (3rd ed.). Upper Saddle River, $\mathrm{NJ}$ : Pearson Education.
Skaalvik, E. (1997). Self-enhancing and self-defeating ego orientation: Relations with task and task avoidance orientation, achievement, selfperceptions, and anxiety. Journal of Educational Psychology, 89, 71-81.

Sterba, S. K., \& Foster, E. M. (2008). Self-selected sample. In P. J. Lavrakas (Ed.), Encyclopedia of Survey Research Methods (pp. 806-808). Thousand Oaks, California: SAGE Publications.

Wigfield, A. (1994). Expectancy-value theory of achievement motivation: A developmental perspective. Educational Psychology Review, 6, 49-78. 
R E S E A R C H

\section{Appendix}

The Argentinean Achievement Goal Questionnare - Revised (A-AGQ-R)

Metas de aproximación-maestría

1. Mi objetivo es llegar a dominar completamente el material presentado en esta clase.

7 Mi propósito es comprender el contenido de esta asignatura tan completamente como sea posible.

3. Mi meta es aprender tanto como sea posible.

Metas de evitación-maestría

5. Mi objetivo es evitar aprender menos de lo que podría.

11. Mi propósito es evitar una comprensión incompleta del material de la asignatura.

9. Mi meta es evitar aprender menos de lo que es posible aprender.

Metas de aproximación-rendimiento

4. Mi objetivo es desempeñarme bien con respecto a otros alumnos.

2. Mi propósito es que me vaya bien comparado con otros alumnos.

8. Mi meta es desempeñarme mejor que los otros alumnos.

Metas de evitación-rendimiento

12. Mi objetivo es evitar que me vaya peor que a otros alumnos.

10. Mi propósito es evitar desempeñarme peor que otros.

6. Mi meta es evitar desempeñarme mal comparado con otros. 